\title{
APLICAÇÃO DO AQUECIMENTO ÔHMICO NA GELATINIZAÇÃO DE AMIDO DE MILHO
}

\author{
G. Z. CAMPOS, J. A. G. VIEIRA* \\ Universidade Estadual Paulista, Departamento de Engenharia e Tecnologia de Alimentos \\ *e-mail: jantonio@ibilce.unesp.br
}

\begin{abstract}
RESUMO
Os amidos têm um papel importante no processamento de alimentos. As propriedades funcionais dos amidos, como a temperatura de gelatinização, formação de gel e viscosidade da pasta determinam sua aplicação industrial. Estas características específicas podem ser obtidas através de modificações físicas e químicas dos grânulos de amido. O tratamento térmico convencional com baixa umidade é um dos métodos utilizados o qual demanda muito tempo e pode chegar a 16 horas e temperaturas acima de $100^{\circ} \mathrm{C}$. O objetivo é determinar os efeitos termodinâmicos de uma suspensão de amido de milho durante a gelatinização por aquecimento ôhmico. Para isso, foi construída uma célula condutivimétrica para determinar esses efeitos. Verificou-se que a condutividade elétrica aumenta com a temperatura e diminui com o aumento do grau de gelatinização do amido de milho, o mesmo ocorreu com a entalpia. Todas as amostras mostraram uma taxa de aquecimento ôhmico semelhante independente do grau de gelatinização.
\end{abstract}

\section{INTRODUÇÃO}

Várias indústrias utilizam amidos em sua produção para diversos fins. Dependendo de sua aplicação e função, estes amidos devem apresentar características funcionais específicas, o que impulsiona o estudo e a caracterização de amidos de diferentes fontes. Estas características específicas podem ser obtidas de amidos de diferentes fontes botânicas ou através de modificações químicas e físicas dos grânulos de amido (LEONEL e CEREDA, 2002, JYOTHI, SAJEEV e SREEKUMAR, 2010).

Há dois tratamentos hidrotérmicos que modificam as propriedades termodinâmicas do amido sem destruir a estrutura do grânulo, o anneling e o tratamento térmico com baixa umidade. Este último demanda longo tempo podendo chegar a 16 horas e temperaturas acima de $100^{\circ} \mathrm{C}$. (JACOBS e DELCOUR, 1998).

$\mathrm{O}$ aquecimento do gel de amido requer tempos maiores que o amido não gelatinizado em situações semelhantes de fornecimento de energia, já que a transferência de calor ocorre através da condução e que as condutividade e difusividade térmica são menores nos géis. $\mathrm{Na}$ gelatinização convencional, o produto é aquecido em trocadores de calor fazendo uso de condução ou de convecção. A transferência de calor do amido no estado de gel é menor do que no não gelatinizado, resultando em tempos longos de aquecimento.

No aquecimento ôhmico, o calor é gerado internamente pela passagem de uma 
corrente alternada através do alimento, que em sua maioria, contêm espécies de eletrólitos, tais como sais e ácidos. O processo de aquecimento ôhmico é um meio para o emprego do HTST (high temperature, short time) em alimentos particulados, pois, desde que a condutividade em ambas as fases seja a mesma, o calor a ser gerado nestas terá a mesma velocidade (HALDEN, DE ALWIS e FRYER, 1990). Desta forma, eliminam-se as superfícies de transferência de calor e, assim, aumenta-se a retenção de nutrientes, sendo possível preservarem mais a textura do alimento.

Wang e Sastry (1997) verificaram que ocorreram mudanças na taxa de aquecimento do amido de batata submetido ao aquecimento ôhmico, mostrando que a alteração na taxa se deve a gelatinização do amido. Isto se deve a variação da condutividade elétrica, que é afetada pelo conteúdo iônico, mobilidade da umidade e estrutura física (Palaniappan e Sastry, 1991; Pelacani e Vieira 2003).

O objetivo é verificar o efeito do grau de gelatinização e da temperatura sobre a condutividade elétrica de uma suspensão de amido de milho durante o aquecimento ôhmico.

\section{METODOLOGIA}

Foi utilizado, neste trabalho, amido de milho produzido no laboratório. $\mathrm{O}$ amido foi misturado em água destilada na proporção de 1:5 (p/p). Para aumentar a condutividade elétrica durante o aquecimento ôhmico, uma pequena quantidade de cloreto de sódio (1\% $\mathrm{p} / \mathrm{p}$ ) foi adicionada à suspensão de amido. As amostras foram compostas por amido não gelatinizado, parcialmente e totalmente gelatinizado. A gelatinização parcial e total das amostras foi preparada por preaquecimento ôhmico até atingir temperaturas de 70 e $90^{\circ} \mathrm{C}$, respectivamente, conforme Wang e Sastry (1997). O grau de gelatinazação da solução de amido de cada amostra foi determinado por DSC (Du Pont 9900 Differential Thermal Analyzer) com aquecimento de $10^{\circ} \mathrm{C} / \mathrm{min}$, em duplicata. A energia de gelatinização $\left(\Delta \mathrm{H}_{\mathrm{G}}\right)$ foi determinada pela integração da área do pico e o grau de gelatinização (\%SG) foi determinado comparando o $\Delta \mathrm{H}_{\mathrm{G}}$ da amostra não gelatinizada.

A célula condutivimétrica foi construída em teflon medindo $28,5 \mathrm{~cm}$ de comprimento, com diâmetro interno de 3,0 $\mathrm{cm}$ e diâmetro externo de $4,5 \mathrm{~cm}$. O teflon é bastante inerte, é resistente a temperaturas mais elevadas, e é um bom isolante elétrico Os eletrodos de titânio foram posicionados dentro da célula a uma distância de $100 \mathrm{~mm}$. A temperatura é registrada por um termopar do tipo T. Um circuito semelhante ao de Mitchell e Alwis (1989), foi montado, para variação da voltagem de 0 a $220 \mathrm{~V}$, e frequência de $60 \mathrm{~Hz}$.

A célula foi calibrada com soluções salinas em diferentes concentrações. A condutividade elétrica dessas soluções foi medida por um condutivímetro comercial calibrado da marca Analion, modelo C702.

A condutividade elétrica das amostras foi calculada de acordo com os dados obtidos de voltagem e de corrente, aplicando as seguintes equações:

$\mathrm{Q}=\mathrm{IR}$

$\mathrm{R}=\mathrm{L} /(\mathrm{A} \sigma)$

$\sigma=(1 / \mathrm{R}) \cdot \mathrm{K}_{\mathrm{c}}$

$\sigma=(\mathrm{I} / \mathrm{V}) .(\mathrm{L} / \mathrm{A})$

onde Q é o calor gerado, I é a corrente, $\mathrm{R}$ é a resistência, V é a voltagem, L é a distância dos eletrodos $(\mathrm{m})$ e A é área $\left(\mathrm{m}^{2}\right)$ do eletrodo. Usando análise dimensional, a condutividade elétrica é expressa em Siemens/metro (S/m).

\section{RESULTADOS E DISCUSSÕES}


Para a verificação da precisão da célula condutivimétrica, foi medida a condutividade elétrica de uma solução salina em três concentrações, com o uso de um condutivímetro comercial, devidamente calibrado com solução padrão e com a célula condutivimétrica. Os resultados são mostrados na Tabela 1.

Tabela 1- Mostra de condutividade elétrica de uma solução salina medida no condutivímetro comercial e na célula condutivimétrica.

\begin{tabular}{llccl}
\hline $\begin{array}{l}\text { Solu- } \\
\text { ção }\end{array}$ & $\begin{array}{l}\text { Concen- } \\
\text { tração } \\
(\mathrm{M})\end{array}$ & $\begin{array}{c}\text { Conduti- } \\
\text { vímetro } \\
\text { Comercial } \\
\sigma(\mathrm{S} / \mathrm{m})\end{array}$ & $\begin{array}{c}\text { Célula } \\
\text { Conduti- } \\
\text { vimétrica } \\
\sigma(\mathrm{S} / \mathrm{m})\end{array}$ & $\begin{array}{l}\text { Dife- } \\
\text { rença } \\
(\%)\end{array}$ \\
\hline & 0.02 & 0,326 & 0,346 & 6,1 \\
$\mathrm{NaCl}$ & 0.05 & 0,745 & 0,785 & 5,4 \\
& 0.17 & 1.750 & 1.790 & 2,3 \\
\hline
\end{tabular}

A Figura 1 mostra o comportamento das amostras de amido de milho, quando submetidas ao aquecimento ôhmico. Todas as amostras apresentam uma taxa de aquecimento ôhmico semelhante independente do grau de gelatinização. Isto torna o processo mais rápido em relação ao convencional. Conforme é observado por vários autores durante o aquecimento ôhmico de alguns alimentos (HANDEN, DE ALWIS e FRYER, 1990, PELACANI e VIEIRA, 2003). Wang e Sastry (1997) verificaram que ocorreram mudanças na taxa de aquecimento do amido de batata submetido ao aquecimento ôhmico, mostrando que a alteração na taxa se deve a gelatinização do amido.

As curvas de condutividade elétrica com a temperatura em função do grau de gelatinização são mostradas na Figura 2. Os resultados mostram que a condutividade aumenta com a temperatura, em todas as suspensões, mas diminui com o grau de gelatinização das mesmas.

$\mathrm{Na}$ amostra não gelatinizada observase que na temperatura $75^{\circ} \mathrm{C}$ ocorre uma diminuição da condutividade elétrica, devido à mudança da estrutura com gelatinização do amido. O mesmo foi observado Wang e Sastry (1997) durante o aquecimento ôhmico de uma suspensão de amido de batata.

Figura 1- Variação da condutividade elétrica durante o aquecimento ôhmico do amido de milho em diferentes graus de gelatinização.

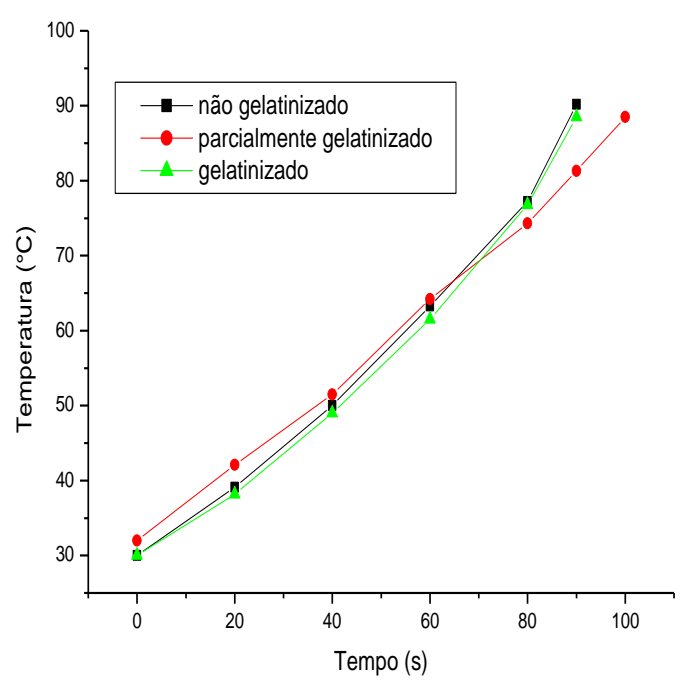

Neste trabalho verificou a similaridade na forma e localização do pico endotérmico do DSC com as curvas da condutividade elétrica. Existe assim, um potencial para usar a condutividade na determinação do $\Delta \mathrm{H}_{\mathrm{G}}$ da amostra de amido. Verificou que a taxa de aquecimento aumenta inexplicavelmente com a gelatinização do amido. Embora a mobilidade da água diminua com a gelatinização, ela aumenta com aumento da temperatura. Este fenômeno pode explicar o aumento da taxa de aquecimento ôhmico com aumento da temperatura. Dados de \%SG determinado por termogramas do DSC e as curvas de condutividade correspondem bem em faixas de baixa e médio-gelatinização; no entanto, resultados diferentes foram 
encontrados no alto \% SG. provavelmente por causa da taxa de aquecimento elevado de aquecimento ôhmico.

Figura 2- Efeito da temperatura na condutividade elétrica de suspensões de amido de milho.

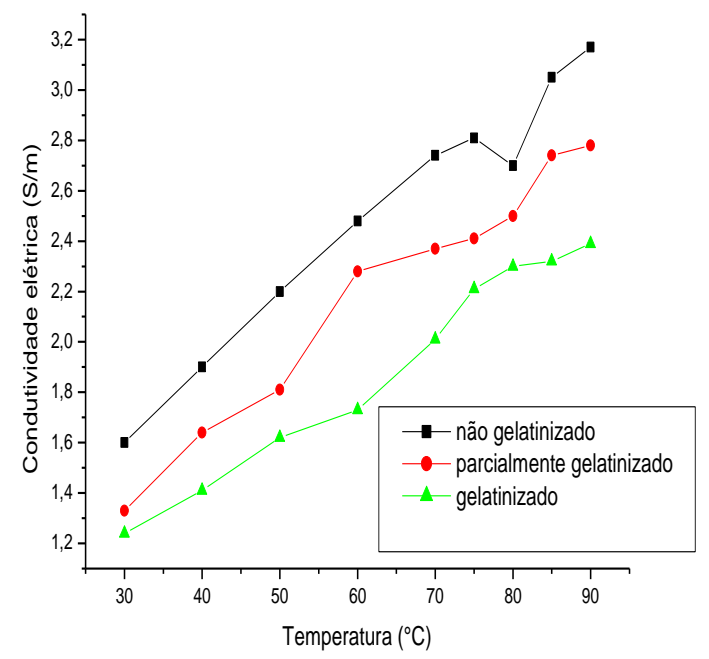

\section{CONCLUSÃO}

A condutividade aumenta com a temperatura em todas as amostras. Mas quanto menor o grau de gelatinização maior é a condutividade elétrica do amido de milho. Observa uma sincronização na mudança da condutividade com gelatinização do amido. Todas as amostras apresentam uma taxa de aquecimento ôhmico semelhante independente do grau de gelatinização. Sendo que, quanto maior o grau de gelatinização maior a taxa de aquecimento.

\section{REFERÊNCIAS}

HALDEN, K.; De ALWIS, A.A.P.; FRYER, P.J. Changes in the eletrical conductivity of during ohmic heating. International Journal of Food and Technology, v.25, p.925, 1990.
JACOBS, H.; DELCOUR, J.A. Hidrothermal modifications of granular starch, with retention of the granular structure: A review. Journal of Agricultural and Food Chemistry. V.46, p.2895-2905, 1998.

LEONEL, M.; CEREDA, M.P. Caracterização físico-química de algumas tuberosas amiláceas. Ciência e Tecnologia de Alimentos, v.7, p.65-69, 2002.

JYOTHI, A.N.; SAJEEV, M.S.; SREEKUMAR, J.N. Hydrothermal modifications of tropical tuber starches. I Effect of heat-moisture treatment on the physicochemical, rheological and gelatinization characteristics. Starch/ stärke, v.62, p. 28-40, 2010.

MITCHELL, F.R.G.; ALWIS, A.A.P. Electrical conductivity meter for food samples. Journal of Physica, v.22, p.554556, 1989.

PALANIAPPAN, S.; SASTRY, S.K. Electrical conductivity of selected solid foods during ohmic heating. Journal of Food Process Engineering, v.14, p.2321-2360. 1991.

PELACANI, V.; VIEIRA, J.A.G. Aquecimento ôhmico de suco de manga. Revista Alimentos e Nutrição, v.14, 39-46, 2008.

VIEIRA, F.C.; SARMENTO, S.B.S. Heatmoisture treatment and enzymatic digestibility of peruvian carrot, sweet potato and ginger starches. Starch/ stärke, v.60, p.223-232, 2008.

WANG, W.; SASTRY, S. K. Starch Gelatinization in Ohmic Heating. Journal of Food Engineering, v.34, p.225-242, 1997.

\section{AGRADECIMENTO}


À FUNDUNESP pelo auxílio financeiro para a realização do trabalho e apresentação do mesmo. 